\title{
Investigation on internal structure of pellets with halloysite additive and effect of moisture content before the pelletizing process
}

\author{
Joanna Wnorowska ${ }^{1 *}$, Mateusz Tymoszuk ${ }^{1}$, and Sylwester Kalisz ${ }^{1}$ \\ 1 Silesian University of Technology, Institute of Power Engineering and Turbomachinery, \\ ul. Konarskiego 20 44-100 Gliwice.
}

\begin{abstract}
The article presents analysis of the particle size distribution inside pellets and the influence of moisture content before pelletization process on final product mechanical strength. The following types of biomass were used without and with the content of additive (halloysite): Polish wheat straw - (SP-K), miscanthus (DM), cereal straw (DS) and herbaceous pellets (BZ). Particles inside pellets were characterized by a grain size smaller than $3 \mathrm{~mm}$ and the cumulative weight percent passing through the sieve with mesh screen $1 \mathrm{~mm}$ for each sample was higher than $70 \%$. The moisture content before pelletization process for tested materials was in the range of $25 \%-30 \%$ depending on the material which was used, while values of mechanical strength of pellets were within the range of $77.7 \%-96.2 \%$ (depending on the type of material and moisture content before the pelletization process).
\end{abstract}

\section{Introduction}

Restrictions related to biomass combustion, such as different elemental composition, a relatively high chlorine content, as well as a different chemical composition of ash compared to fossil fuels resulting in hazards for the boiler and its auxiliary installations [1], contribute to the creation of new technological solutions in the energy sector. An example of this is the development of biomass pre-treatment processes before its energy use. One of these processes is the palletization of biomass enabling for application of fuel additives. During pelletization the raw material is subjected to a series of processes, among which one can distinguish: grinding, conditioning (application of heat and/or moisture, use of fuel additives), granulation and cooling. Each of these stages has a significant impact on the final effect of the pelletization process. In addition, the pelletization allows to increase the density of fuel and allows its cheaper and safer transport. Therefore, the aim of the research was to determine the internal structure of pellets, as well as the influence of moisture content before the pelletizing process on the final product. The following types of biomass were used without and with the content of fuel additive (halloysite): Polish wheat straw - (SP-K), miscanthus (DM), cereal straw (DS) and herbaceous pellets (BZ).

\footnotetext{
* Corresponding author: joanna.wnorowska@polsl.pl
} 


\section{Methodology of research}

\subsection{Particle size distribution inside pellets}

The size of the initial particles inside pellets is an important aspect due to the processes occurring in power plants, such as grinding of pellets and subsequent firing of pulverized biomass.. In [2] a comparison of several methods of pellet decomposition from biofuels to determine their internal grain distribution is given. The methods presented are based on the wet decay of pellets in water, followed by drying and sieving or on dry disintegration consisting of crushing pellets in a laboratory hammer mill and sieving particles. After comparing the methods, the authors concluded that wet disintegration is the most appropriate method for the breakdown of biofuel pellets. It was also found that this method combined with sieve analysis gives a realistic picture of the internal particle size distribution [2].

The recommended size of particles in biofuel pellets is included in the relevant standards - EN 17827 [3] and EN 17830 [4]. These standards are intended to define requirements and methodologies used to determine the particle size of pellets and apply to pellets that are fully decomposable in hot water. There are no restrictions on the presence of small particles inside pellets in international guidelines. However, most standards state that $50 \%$ of particles should be less than $1 \mathrm{~mm}$ in size. However, there is a discussion about the amount of very small particles in biomass pellets because of the danger of dust explosion that can separate from pellets during transport or storage. The prepared sample was left until it was completely disintegrated ( 2 hours). The next stage was drying. The suspension formed in the disintegration process was mixed well and transferred to drying containers. The sample was dried in an oven at a temperature not higher than $60^{\circ} \mathrm{C}$. This operation was continued until the humidity reached $5 \%$ to $15 \%$. After drying, the sample was mixed and placed in a room atmosphere for 2 hours. Then it was divided into two parts, about $150 \mathrm{~g}$ each. The first part was used to check the humidity level by ISO 18134 -: 2015-11 [5]. The second one was divided into four equal parts to perform sieve analysis. Next, each test portion was sieved using the Multiserw LPZB-2e pneumatic sieving machine with a set of following sieves: $0.25,0.5,1.0,1.5,2.0$ and $3.0 \mathrm{~mm}$. These activities were repeated for all types of biomass.

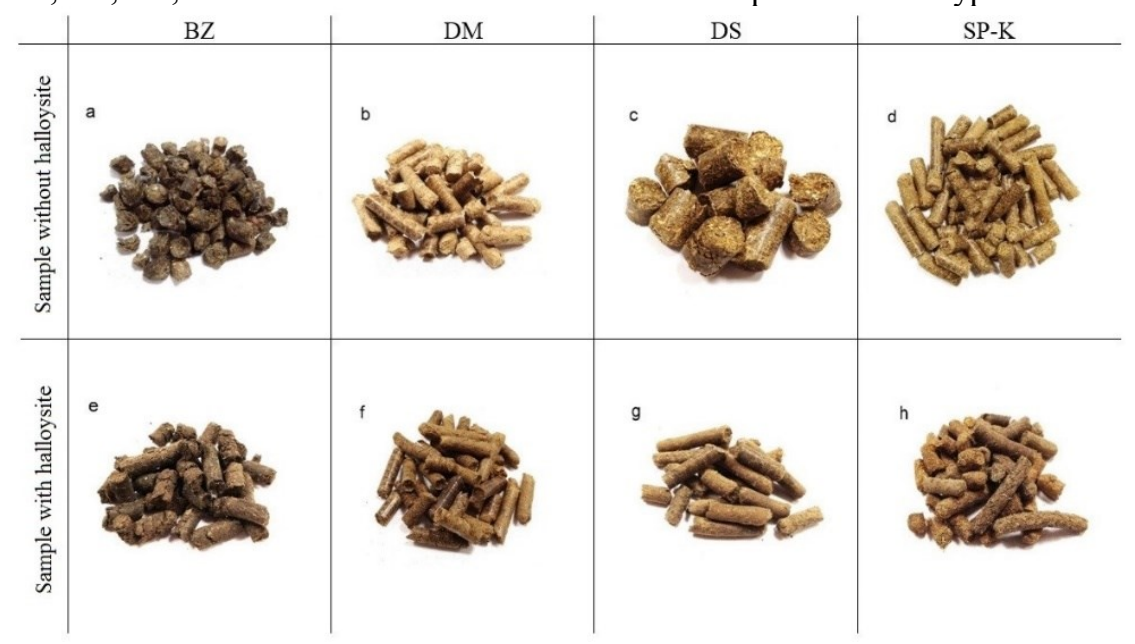

Fig.1. Samples used during researches on particle size distribution inside pellets (a - BZ "0", b - DM "0", c - DS "0", d - SP-K "0", e - BZ "2", f - DM "4", g - DS "4", h - SP-K "4"), “0" - without halloysite, "2" - 2wt.\% halloysite, "4" - 4wt.\% halloysite. 


\subsection{Effect of moisture content}

An important biomass initial parameter for obtaining good quality pellets is the moisture content of the raw material being pelletized. It has a significant impact on the strength of the pellets, as well as the pelletizing process itself and associated process hurdles.

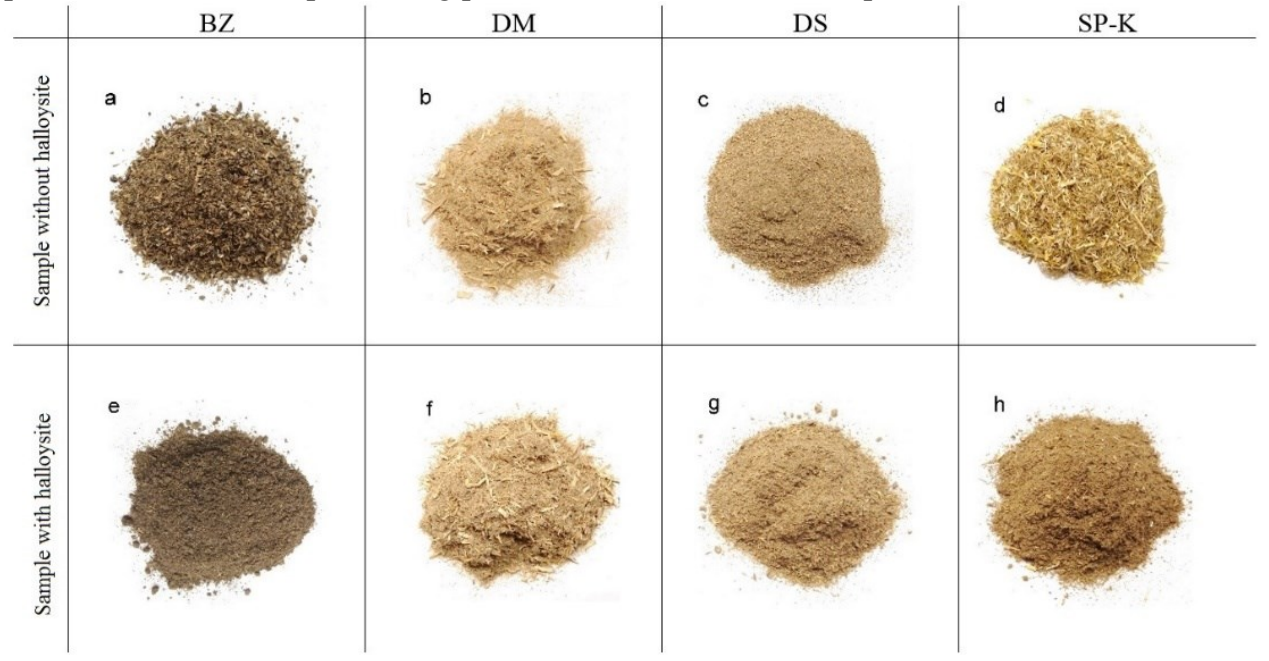

Fig. 2. Samples used during researches on the influence of moisture content before pelleting on the final product (a - BZ "0", b - DM "0", c - DS "0", d - SP-K "0", e - BZ "2 ", F - DM" 4 ", g - DS" 4 ", h - SP - K" 4 "), "0" - without halloysite, "2" - 2wt.\% halloysite, "4" - 4wt.\% halloysite.

The research on the influence of moisture content in the raw material to be pelletized took place in four main stages: sample preparation and humidification, moisture measurement, pelletizing and mechanical strength tests. In the beginning, a portion of a properly ground sample was separated, and its initial moisture was tested by ISO 18134-1: 2015-11 [5]. The sample was then moistened and left for 48 hours to allow the biomass to absorb water. After this time, samples were taken to investigate the moisture content (according to [5]), and the rest was subjected to a pelletization process. Pellets thus obtained were left in a room atmosphere to cool down. The preparation of another sample was carried out according to the same procedure, only the amount of water that was added was different.

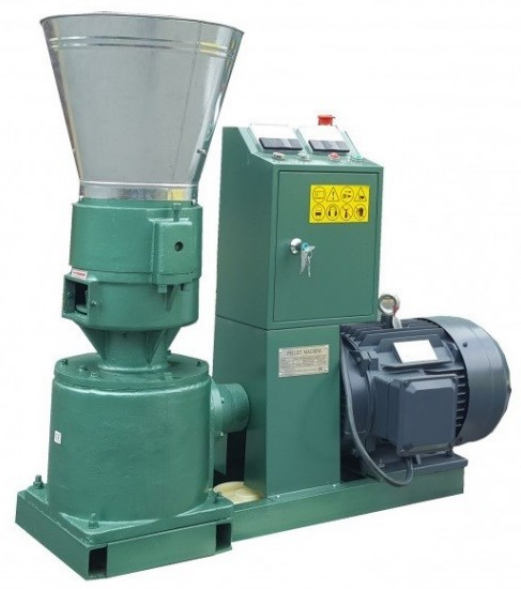

Fig. 3. Pellet making machine WKL - 230B. 
Pelletizing process was carried out using the WKL - 230B pelletizer (Fig. 3.) with the following technical parameters:

- power supply: $380 \mathrm{~V}$ (3 phases),

- electric power: $11 \mathrm{~kW}$,

- output: $150-400 \mathrm{~kg} / \mathrm{h}$ (depending on the material),

- power factor $(\cos \varphi)$ : 0.84 ,

- diameter of finished pellets: $6 \mathrm{~mm}$,

- dimensions: 1140 x 470 x $970 \mathrm{~mm}$,

- weight: $320 \mathrm{~kg}$,

- available pellet diameters: $4 \mathrm{~mm}, 6 \mathrm{~mm}, 8 \mathrm{~mm}$.

To assess the effect of moisture of the raw material before the pelletizing process on the final product, mechanical strength tests of pellets were carried out. These tests were carried out according to the PN-EN ISO 17831-1 [6] standard by an external laboratory (ZPBE ENERGOPOMIAR Sp. z o.o.). The sample supplied for testing was divided into two parts of $500 \mathrm{~g}$, and then each one was placed in a pellet tester - Fig. 4. The box rotation was set at $50 \pm 2 \mathrm{rpm}$ for a total of 500 revolutions. In the next stage of mechanical strength determination, the sample was screened using a sieve with a mesh with a diameter larger than $3.15 \mathrm{~mm}$, so as not to generate new impurities (shaking with about 5-10 circular movements). Then, the material remaining on the sieve was weighed for each sample and the durability according to the formula (1) was calculated. These activities were repeated for each type of samples.

$$
D U=\frac{m_{A}}{m_{E}} \cdot 100, \%
$$

where:

$D U$ - mechanical durability, \%,

$m_{E}-$ mass of the sieved pellets before the tumbling treatment, $\mathrm{g}$,

$m_{A}-$ mass of the sieved pellets after the tumbling treatment, $\mathrm{g}$.

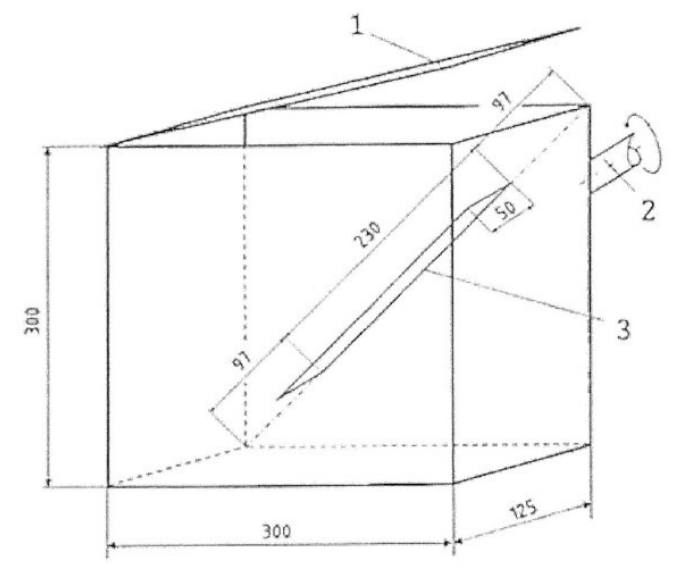

Fig. 4. Structure of the main parts of the pellet strength tester [6]; 1 - filling door, 2 - drive shaft, 3 -baffle.

\section{Test results and conclusions}

Results of proximate and ultimate analyses of fuels used in the research are presented below. Fuels were characterized by a relatively high ash content. 
Table 1 Results of fuel analyses (ar - as received state; $d$ - dry state) Polish wheat straw - (SP-K), miscanthus (DM), cereal straw (DS) and herbaceous pellets (BZ).

\begin{tabular}{l|c|c|c|c|c|c}
\multirow{2}{*}{ Parameter } & \multirow{2}{*}{ Symbol } & \multirow{2}{*}{ Unit } & \multicolumn{5}{c}{ Fuel } \\
\cline { 4 - 7 } & & & BZ & SP-K & DS & DM \\
\hline Moisture content in fuel & $\mathrm{M}^{\text {ar }}$ & $\%$ & 9.2 & 13.6 & 11.7 & 10.2 \\
\hline Ash content in fuel & $\mathrm{A}^{\text {ar }}$ & $\%$ & 4.4 & 5.6 & 9.5 & 3.7 \\
\hline Ash content in fuel & $\mathrm{A}^{\mathrm{d}}$ & $\%$ & 4.9 & 6.5 & 10.8 & 4.2 \\
\hline Higher heating value & $\mathrm{q}_{\mathrm{v}, \mathrm{gr}^{\mathrm{d}}}$ & $\mathrm{MJ} / \mathrm{kg}$ & 19.41 & 18.55 & 17.40 & 18.56 \\
\hline Lower heating value & $\mathrm{q}_{\mathrm{v}, \text { net }}{ }^{\mathrm{d}}$ & $\mathrm{MJ} / \mathrm{kg}$ & 18.19 & 17.35 & 16.27 & 17.35 \\
\hline Carbon content in fuel & $\mathrm{C}^{\mathrm{d}}$ & $\%$ & 47.7 & 45.9 & 44.1 & 50.5 \\
\hline Hydrogen content in fuel & $\mathrm{H}^{\mathrm{d}}$ & $\%$ & 5.92 & 5.82 & 5.49 & 5.87 \\
\hline Nitrogen content in fuel & $\mathrm{N}^{\mathrm{d}}$ & $\%$ & 2.95 & 0.57 & 0.86 & 0.43 \\
\hline Sulphur content in fuel & $\mathrm{S}^{\mathrm{d}}$ & $\%$ & 0.100 & 0.090 & 0.130 & 0.060 \\
\hline Chlorine content in fuel & $\mathrm{Cl}^{\mathrm{d}}$ & $\%$ & 0.085 & 0.188 & 0.433 & 0.094
\end{tabular}

\subsection{Particle size distribution inside pellets}

Results of the particle size distribution in biomass pellets are presented in Table 2. Also, a granulation curve was prepared for the samples (Fig. 5).

Table 2 Results of researches on the particle size distribution inside pellets for all samples.

\begin{tabular}{c|c|r|r|r|r|r|r|r|r}
\multirow{2}{*}{ Sieve } & \multirow{2}{*}{$\begin{array}{c}\text { Fraction, } \\
\text { mm }\end{array}$} & \multicolumn{7}{|c}{ Cumulative weight percent passing through, in \% } \\
\cline { 3 - 10 } & & SP-K 0 & SP-K 4 & DM 0 & DM 4 & \multicolumn{1}{c}{ DS 0 } & \multicolumn{1}{c}{ DS 4 } & \multicolumn{1}{c}{ BZ 0 } & BZ 2 \\
\hline 0 & $\begin{array}{c}\text { below } \\
0.25\end{array}$ & 0 & 0 & 0 & 0 & 0 & 0 & 0 & 0 \\
\hline 0.25 & $\begin{array}{c}0.25 \text { do } \\
0.5\end{array}$ & 38.1 & 41.6 & 56.4 & 54.9 & 20.6 & 42.6 & 39.3 & 55.3 \\
\hline 0.5 & $\begin{array}{c}0.5 \text { do } \\
1.0\end{array}$ & 71.8 & 73.6 & 85.5 & 84.3 & 43.3 & 68.3 & 62.7 & 80.6 \\
\hline 1 & $\begin{array}{c}1.0 \text { do } \\
1.5\end{array}$ & 96.4 & 96.0 & 97.7 & 97.8 & 70.1 & 88.3 & 78.7 & 95.3 \\
\hline 1.5 & $\begin{array}{c}1.5 \text { do } \\
2.0\end{array}$ & 99.0 & 99.1 & 99.3 & 99.5 & 86.2 & 95.5 & 87.4 & 99.4 \\
\hline 2 & $\begin{array}{c}2.0 \text { do } \\
3.0\end{array}$ & 100.0 & 100.0 & 100.0 & 100.0 & 95.4 & 100.0 & 93.0 & 100.0 \\
\hline 3 & above 3.0 & 100.0 & 100.0 & 100.0 & 100.0 & 99.7 & 100.0 & 97.4 & 100.0 \\
\hline
\end{tabular}




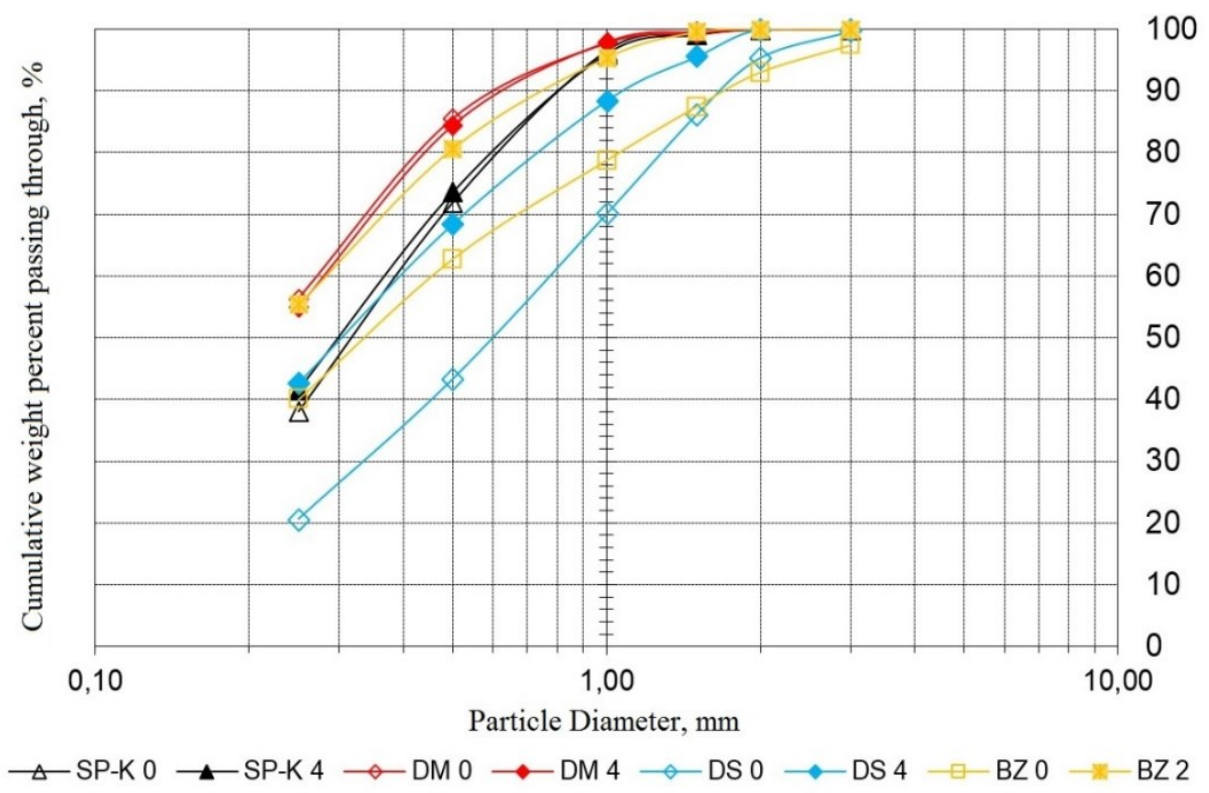

Fig. 5. The particle size distribution curve for samples

In international specifications, there are restrictions on the size of particles inside pellets. It was found that $50 \%$ of the particles should be less than $1 \mathrm{~mm}$. Another requirement that can be found in the literature is a total fraction of less than $3 \mathrm{~mm}$ to obtain a compact and hard pellet.

Comparing results obtained for samples in the form provided for research, one can not notice significant differences in the distribution of internal particles between fuels with and without the content of halloysite. According to Fig. 5, all samples have a particle size below $3 \mathrm{~mm}$ and the mass fraction passing through the mesh with a diameter $1 \mathrm{~mm}$ for each sample is above $70 \%$. Therefore, it can be concluded that pellets with halloysite additive met requirements of relevant standards.

The small particle size that can be seen in samples is advantageous for pellets, because it causes larger external particle surface, and thus better compression of pellets. This improves the quality of pellets and allows them to achieve higher density. Also, during tests, it was noticed that the content of halloysite had no significant effect on the particle size distribution inside the pellets. Possible differences may result from the use of different preparation methods and sizes of pellets used (DS 0 and BZ 0 were tested in the form of pellets delivered for testing, while the rest of samples were delivered in a loose form and were pelletized with the additive supplier). 


\subsection{Effect of moisture content}

Samples in the form of pellets have been fragmented by the additive supplier. Then, in the form provided for testing (Fig. 2), they were subjected to sieve analysis. The obtained results are shown in Table 3. Also, a particle size distribution curve was prepared for the samples before pelletizing (Fig. 6).

Table 3 Sieve analysis of samples before the pelletization process.

\begin{tabular}{c|c|r|r|r|r|r|r|r|r}
\multirow{2}{*}{ Sieve } & \multirow{2}{*}{$\begin{array}{c}\text { Fraction, } \\
\text { mm }\end{array}$} & \multicolumn{8}{|c|}{ Cumulative weight percent passing through, in \% } \\
\cline { 3 - 10 } & SP-K 0 & SP-K 4 & DM 0 & DM 4 & DS 0 & DS 4 & BZ 0 & BZ 2 \\
\hline 0 & below 0.25 & 0.0 & 0.0 & 0.0 & 0.0 & 0.0 & 0.0 & 0.0 & 0.0 \\
\hline 0.25 & 0.25 do 0.5 & 14.1 & 51.7 & 35.2 & 36.3 & 27.0 & 27.5 & 10.5 & 26.4 \\
\hline 0.5 & 0.5 do 1.0 & 24.9 & 73.1 & 68.3 & 68.7 & 51.2 & 51.6 & 26.7 & 46.1 \\
\hline 1 & 1.0 do 1.5 & 39.8 & 89.5 & 79.7 & 79.6 & 73.2 & 73.4 & 51.6 & 69.4 \\
\hline 1.5 & 1.5 do 2.0 & 70.5 & 95.6 & 85.5 & 88.5 & 85.2 & 85.3 & 69.0 & 82.5 \\
\hline 2 & 2.0 do 3.0 & 91.8 & 98.0 & 90.3 & 90.4 & 93.1 & 93.2 & 83.6 & 90.9 \\
\hline 3 & above 3.0 & 98.1 & 99.7 & 96.1 & 96.0 & 98.4 & 98.2 & 97.7 & 95.8
\end{tabular}

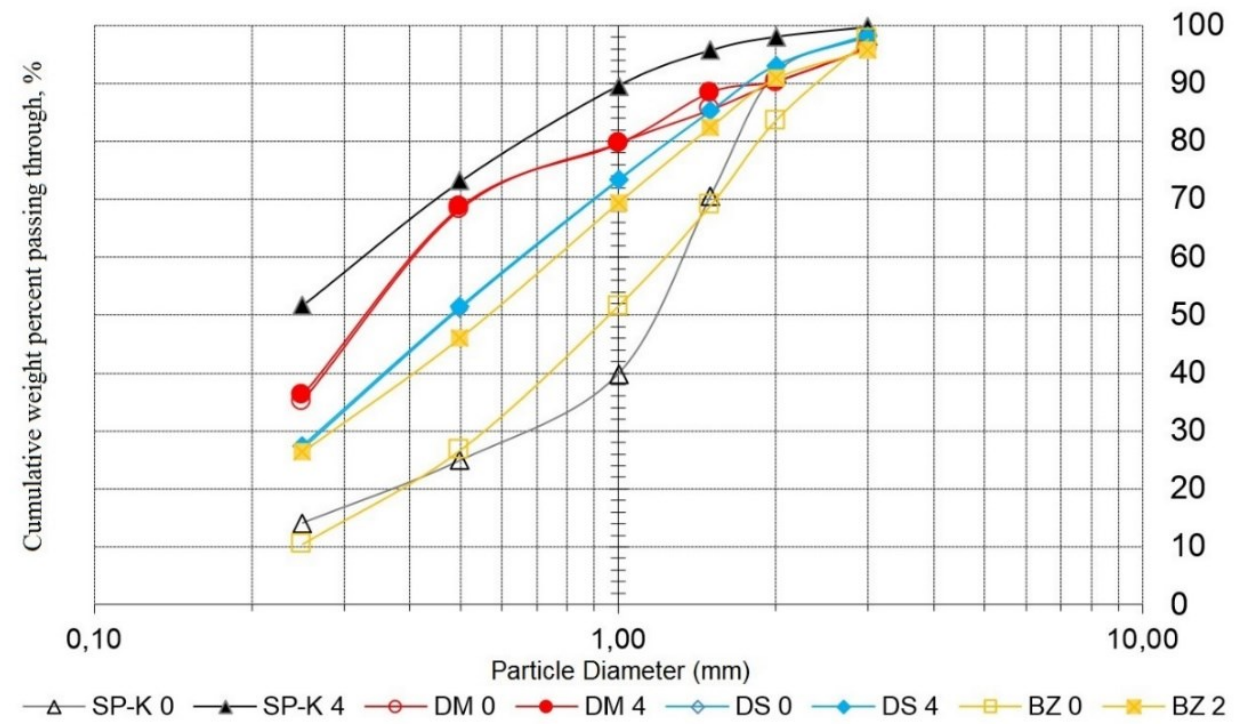

Fig. 6. The particle size distribution curve of samples before the pelletization process.

Analyzing obtained results (Fig. 6) it was observed that each sample subjected to sieve analysis has the majority of particles smaller than $3 \mathrm{~mm}$, whereas the percentage mass fraction is passing through the $1 \mathrm{~mm}$ sieve is greater than $40 \%$. Also, it was noted that the addition of halloysite does not affect the particle size distribution curve for the particular type of biomass used (best seen on the example of DM and DS, where the distribution curves almost coincide). 
The moisture content was determined in samples provided for testing (Table 4), then each was divided into two parts and sprayed with water to obtain two different wetting levels. The moisture content was again determined, and obtained results were listed in Table 5.

Table 4 Initial moisture content in samples provided for testing.

\begin{tabular}{c|c|c|c|c|c|c|c|c}
\multirow{2}{*}{} & SP-K 0 & SP-K 4 & DM 0 & DM 4 & DS 0 & DS 4 & BZ 0 & BZ 2 \\
\cline { 2 - 9 } & 10.0 & 12.0 & 7.0 & 8.7 & 8.5 & 9.7 & 9.4 & 15.1
\end{tabular}

Table 5 Moisture content after moisturizing and before the pelletization process (I and II indicate different moisture contents).

\begin{tabular}{c|c|c|c|c|c|c|c|c} 
SP-K 0 & SP-K 0 & DM 0 & DM 0 & DS 0 & DS 0 & BZ 0 & BZ 0 \\
I & II & I & II & I & II & I & II \\
\cline { 2 - 9 } & 35.7 & 46.0 & 22.6 & 29.9 & 23.4 & 34.0 & 23.3 & 30.2 \\
\cline { 2 - 9 } & $\begin{array}{c}\text { SP-K 4 } \\
\text { I }\end{array}$ & $\begin{array}{c}\text { SP-K 4 } \\
\text { II }\end{array}$ & $\begin{array}{c}\text { DM 4 } \\
\text { I }\end{array}$ & $\begin{array}{c}\text { DM 4 } \\
\text { II }\end{array}$ & $\begin{array}{c}\text { DS 4 } \\
\text { I }\end{array}$ & $\begin{array}{c}\text { DS 4 } \\
\text { II }\end{array}$ & $\begin{array}{c}\text { BZ 2 } \\
\text { I }\end{array}$ & $\begin{array}{c}\text { BZ 2 } \\
\text { II }\end{array}$ \\
\cline { 2 - 9 } & 27.4 & 38.0 & 22.7 & 35.4 & 21.8 & 27.5 & 22.8 & 29.1
\end{tabular}

After 48 hours, samples were pelletized and then left in an ambient atmosphere to cool. Obtained effects are shown in Fig. 7. Based on conducted tests, it can be noticed that not all of the samples were fully pelletized. This is the result of the degree of wetness and fragmentation of the samples. During tests, it was noticeable that too coarsely ground sample causes additional milling of the material through rollers of the pelletizing machine, whereas too high humidity causes longer drying, which results in a longer time of material remaining in the pelletizing machine. Both too low and too high humidity leads to difficulties during the pelletizing process, which result in the form of unpelletized material that can be seen in Fig. 7. An example is the DM "0" I sample, which was too dry and the sample SP-K "0" II, which was too wet. 


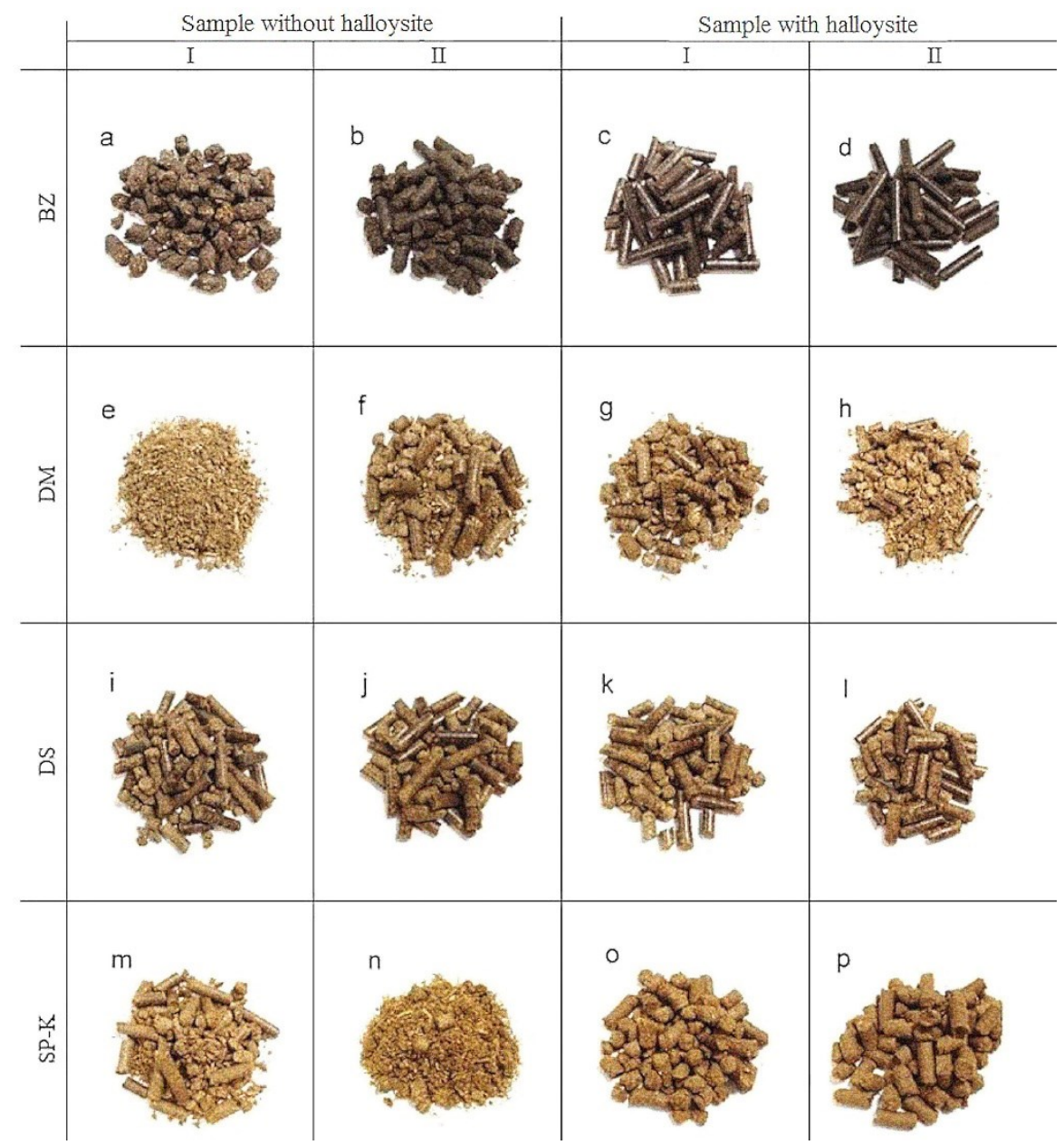

Fig. 7. Final product after the pelletization process (a - BZ "0" I, b - BZ "0" II, c - BZ "2" I, d - BZ "2" II, e - DM "0" I, f - DM "0" II, g - DM "4" I, h - DM "4" II, and - DS "0" I, j - DS "0" II, k - DS "4" I, 1 - DS " 4 "II, m - SP- K" 0 "I, n - SP-K" 0 "II, o - SP-K" 4 "I, p - SP-K" 4 "II) (I and II mean different moisture content according to Table 5).

Next, it was estimated if more than $50 \%$ of the pelletized sample is in the form of pellets. Samples that did not meet this condition were rejected (SP-K "0" II, DM "0" I, DM "0" II and DM "4" II). The remaining ones were tested for mechanical strength of pellets (according to PN-EN 15210-1: 2010 [5]) by an external laboratory (ZPBEENERGOPOMIAR Sp. z o.o.). Obtained results are shown below. 


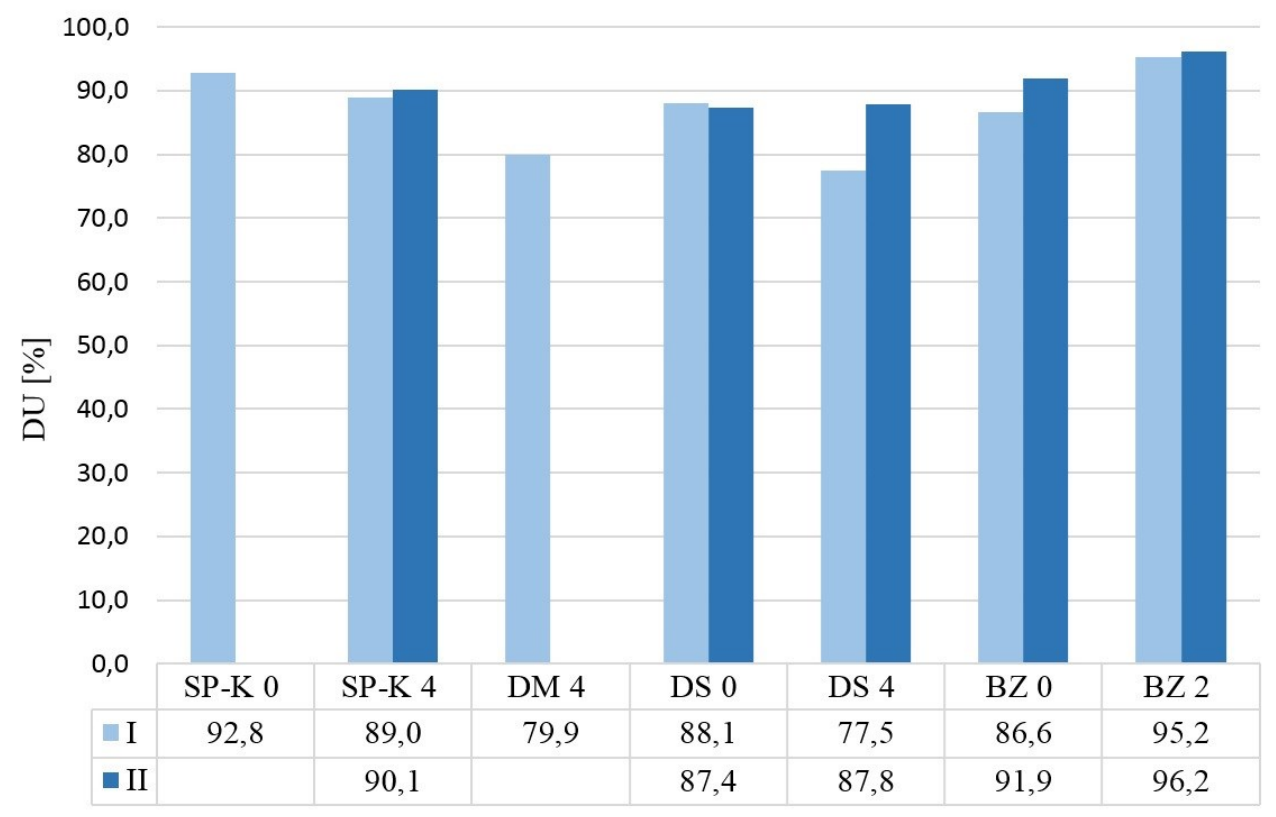

Fig. 8. Mechanical strength of pellets (I and II indicate different moisture contents according to Table 5)

Based on obtained results (Fig. 8), it can be concluded that for all samples, mechanical strength ranges from $77 \%$ - 96\%. The obtained values of mechanical strength differ depending on the type of material and the moisture content before the pelletizing process. The lowest mechanical strength values were recorded for DS "4" with $21.8 \%$ humidity (DU $=77.5 \%)$ and DM "4" with a water content of $22.7 \%$ (DU $=79.9 \%)$. However, remaining types of pellets showed mechanical strength above $86.6 \%$. The closest mechanical strength to the standard value for non-wood pellets ( $\mathrm{DU}=96 \%$ ) [8] have BZ "2" pellets with a moisture content of $29.1 \%$ (DU $=96.2 \%$ ).

The behaviour of the material remaining in the matrix of the pelletizing machine after the pelletizing process was also observed (Fig.9). In the case of a too moist sample, the volume increase was noted, while the excessively dry material compacted in matrix holes. 

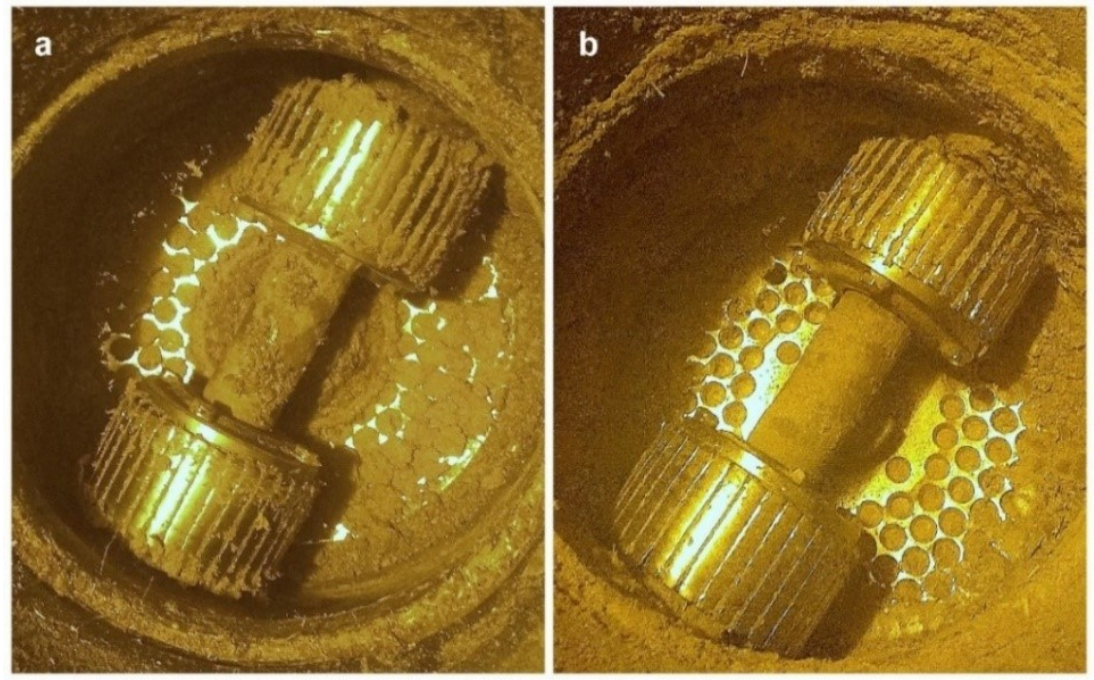

Fig. 9. Matrix of a pellet making a machine with a roller ( $\mathrm{a}$ - too high humidity, $\mathrm{b}$ - too low humidity)

\section{Summary}

The production of pellets from bio originated raw materials is more and more common in energy production. Therefore, it is necessary to optimize the process regarding their use by potential recipients. It is important to obtain high density and high durability for mechanical operations occurring, among others, during transport or reloading, also for pellets containing fuel additives.

During tests, the particle size distribution inside pellets and the influence of the moisture content before pelletizing process on the final product were determined. Among the produced pellets, the best effects regarding pelletizing and the final product were obtained in the case of BZ samples (herbaceous pellets), while the biggest problems were noted for DM samples (miscanthus). It was also noted that pelletized raw materials require fine grinding to a particle size of 3-5 mm before the pelletizing process and suitable moisture content of $25 \%$ to $30 \%$ depending on the material used, to obey DIN plus certification for wood pellets [8].

Conducted tests also allow stating that during pelletizing it is necessary to pay attention to the mechanical strength of pellets because it has a significant impact during transport and storage. Also, a too small particle diameter fraction in pellets increases the risk of explosion. There was no significant effect of fuel additive in the form of halloysite on the verified parameters. Obtained results may provide important information for biomass pellet producers.

\section{Acknowledgment}

Investigation presented in this paper was performed within project: "Advanced pretreatment and characterization of Biomass for Efficient Generation of heat and power" (BioEffGen) funded by The National Centre for Research and Development within Polish-German Sustainability Research Programme (STAIR). 


\section{References}

1. M. Kopczyński, J. Zuwała, Polityka Energetyczna, Biomass torrefaction as a way for elimination of technical barriers existing in large-scale co-combustion, 16, 271-284 (2013).

2. P. D. Jensen, M. Temmerman, S. Westborg, Fuel, Internal particle size distribution of boifuel pellets, 50, 980-986, (2011).

3. EN 17827 Solid biofuels - Determination of particle size distribution for uncompressed fuels.

4. EN 17830 Solid biofuels - Particle size distribution of disintegrated pellets.

5. ISO 18134-1:2015: Solid biofuels - Determination of moisture content - Oven dry method - Part 1: Total moisture - Reference method.

6. PN-EN ISO 17831-1:2015: Solid biofuels - Determination of mechanical durability of pellets and briquettes - Part 1: Pellets.

7. PN-EN ISO 17225-6 Solid biofuels - Fuel specifications and classes - Part 6: Graded non-woody pellets.

8. Certification DIN plus for wood pellets, (2010). 